\title{
Molecular mechanisms of right ventricular dysfunction in pulmonary arterial hypertension: focus on the coronary vasculature, sex hormones, and glucose/lipid metabolism
}

\author{
Vineet Agrawal $^{1}$, Tim Lahm², Georg Hansmann ${ }^{3}$, Anna R. Hemnes ${ }^{4}$ \\ ${ }^{1}$ Division of Cardiology, Department of Medicine, Vanderbilt University Medical Center, Nashville, TN, USA; ${ }^{2}$ Department of Medicine, Indiana \\ University, Indianapolis, IN, USA; ${ }^{3}$ Department of Pediatric Cardiology and Critical Care, Hannover Medical School, Hannover, Germany; \\ ${ }^{4}$ Division of Allergy, Pulmonology and Critical Care, Department of Medicine, Vanderbilt University Medical Center, Nashville, TN, USA \\ Contributions: (I) Conception and design: All authors; (II) Administrative support: None; (III) Provision of study materials or patients: None; (IV) \\ Collection and assembly of data: All authors; (V) Data analysis and interpretation: All authors; (VI) Manuscript writing: All authors; (VII) Final \\ approval of manuscript: All authors. \\ Correspondence to: Vineet Agrawal, MD, PhD. Division of Cardiology, Department of Medicine, Vanderbilt University Medical Center, 2220 Pierce \\ Ave., 383 Preston Research Building, Nashville 37232-6300, TN, USA. Email: vineet.agrawal@vumc.org.
}

\begin{abstract}
Pulmonary arterial hypertension $(\mathrm{PAH})$ is a rare, life-threatening condition characterized by dysregulated metabolism, pulmonary vascular remodeling, and loss of pulmonary vascular cross-sectional area due to a variety of etiologies. Right ventricular (RV) dysfunction in PAH is a critical mediator of both long-term morbidity and mortality. While combinatory oral pharmacotherapy and/or intravenous prostacyclin aimed at decreasing pulmonary vascular resistance (PVR) have improved clinical outcomes, there are currently no treatments that directly address RV failure in PAH. This is, in part, due to the incomplete understanding of the pathogenesis of RV dysfunction in PAH. The purpose of this review is to discuss the current understanding of key molecular mechanisms that cause, contribute and/or sustain RV dysfunction, with a special focus on pathways that either have led to or have the potential to lead to clinical therapeutic intervention. Specifically, this review discusses the mechanisms by which vessel loss and dysfunctional angiogenesis, sex hormones, and metabolic derangements in PAH directly contribute to RV dysfunction. Finally, this review discusses limitations and future areas of investigation that may lead to novel understanding and therapeutic interventions for RV dysfunction in PAH.
\end{abstract}

Keywords: Pulmonary arterial hypertension (PAH); right ventricular failure (RV failure); sex hormones; metabolism; coronary vasculature

Submitted May 05, 2020. Accepted for publication Jun 04, 2020.

doi: $10.21037 / \mathrm{cdt}-20-404$

View this article at: http://dx.doi.org/10.21037/cdt-20-404

\section{Introduction}

While the pathobiology of pulmonary arterial hypertension (PAH) is complex and incompletely understood, common features of all presentations include a substantial increase in pulmonary vascular resistance (PVR) due to pulmonary vascular remodeling and a concomitant right ventricular (RV) remodeling (1). Notably, among these two manifestations, RV dysfunction (RVD) and RV failure are the major determinants of morbidity and mortality in patients with $\mathrm{PAH}$, in part due to therapeutic advances in improving PVR $(2,3)$. While RV function can significantly be affected by both preload (volume, pressure) and afterload (pressure) conditions in PAH (4), recent evidence suggests that RV dysfunction may occur independent of the loading conditions in PAH. Despite many therapeutic advances in left heart failure, comparatively less is understood regarding the pathobiology of RV dysfunction $(5,6)$.

Studies investigating RV dysfunction in the setting 
of PAH have characterized both adaptive/hypertrophic responses to pressure afterload as well as maladaptive responses such as dilation and pump dysfunction that ultimately lead to clinical heart failure (7). Major factors that have been implicated in maladaptive remodeling of the RV include increased pressure afterload, myocardial hypoxia, and metabolic dysfunction.

A combination of genetic predisposition and initiating/ driving factors such as inflammation, drugs, infections, and sex hormones ultimately results in adverse pulmonary vascular and cardiac remodeling (8-12). This combination of factors ultimately initiates and perpetuates the vicious cycle of RV failure through increased pressure afterload, myocardial hypoxia, and metabolic dysfunction (Figure 1).

The focus of this review is on the molecular mechanisms that may contribute to maladaptive remodeling in the RV. Although many pathways are currently under study in the pathogenesis of RV failure (13-15), this review will specifically focus on select molecular events and pathways that are supported by strong pre-clinical and human (clinical) data that have resulted in, or will lead to, clinical trials in PAH patients.

\section{Dysfunctional coronary artery and capillary formation/angiogenesis}

\section{Micro- and macro-vascular malperfusion/ischemia}

Coronary blood flow and adequate tissue perfusion is thought to be an important component of the myocardium's response to increased workload and hypertrophy in PAH (16-21). Emerging evidence suggests the involvement of macro- and micro-vascular ischemia in the development of RV failure (Figure 2). The combination of increased $\mathrm{RV}$ mass, increased RV workload, and coronary flow impairment causes a significant supply-demand discrepancy (19-21), ultimately leading to maladaptive RV remodeling. Malperfusion/ischemia, and concurrent metabolic changes (outlined later in this review), in the cardiomyocyte are thought to give rise to what is referred to as hibernating myocardium (22). A detailed discussion of the phenotype of hibernating myocytes is beyond the scope of this review, but nicely reviewed elsewhere (22). Notably, mechanisms underlying hibernating myocardium have predominantly been studied in the left ventricle, and considerably less is understood about the pathophysiology of hibernation in the RV. This review will focus on the mechanisms by which coronary macro- and micro-vasculature are altered to ultimately lead to RV failure.

The normotensive RV is perfused during both systole and diastole, and in most instances via the right coronary artery (RCA) arising from the right coronary cusp of the aortic root (23). With systemic or suprasystemic RV pressure, the $\mathrm{RV}$ myocardium is only perfused during diastole, making the blood supply more dependent on lower heart rates and filling time. Moreover, increased RV end-diastolic pressure (RVEDP) and a thick RV myocardium decrease coronary perfusion pressure and flow to the RV myocardium. As demonstrated by non-invasive myocardial perfusion reserve measurement through adenosine challenge, in severe or advanced $\mathrm{PAH}$, there is decreased perfusion reserve in the RV (24). This was more directly demonstrated in a human MRI-based study by van Wolferen et al. that showed both systolic and diastolic flow in the RCA of normal controls, but diastole-predominant flow in the RCA of patients with PAH with an overall decrease in total blood flow to the RV (23). Histologically, post-mortem human and animal model studies have shown increased thickness of epicardial arteries in PAH (25). While layer-specific (e.g., intima, media, or adventitia) changes were not delineated, increased a-SMA staining, IL-6 mRNA, DNA damage, and proinflammatory epigenetic modifier BRD4 were found in arteries from $\mathrm{PAH}$ patients, suggesting inflammation and smooth muscle hyperplasia as important contributors to coronary remodeling (25).

\section{The role of microvascular ischemia in $R V$ failure}

In addition to the large epicardial arterial changes noted above, studies have suggested prominent microvascular changes in the RV in PAH, similar to established studies of microvascular rarefaction and dysfunction in left ventricular (LV) failure (16-18,26,27). Indeed, using traditional twodimensional sections, several studies identified vascular rarefaction in models of RV failure (28-34). In contrast, models of compensated RV hypertrophy [chronic hypoxia, mild pulmonary artery banding (PAB)] demonstrated maintained or increased angiogenesis $(28,29,35,36)$, suggesting a mechanistic link between microvascular density/function and RV failure development. While it is not clear whether microvascular dysfunction is merely a marker of or a contributor to RV failure, experimental approaches to improve $\mathrm{RV}$ vascularization through therapies such as delivery of miR-126 in an experimental model of PH have demonstrated increased RV vascularity/ function without changes in the pulmonary vasculature, 


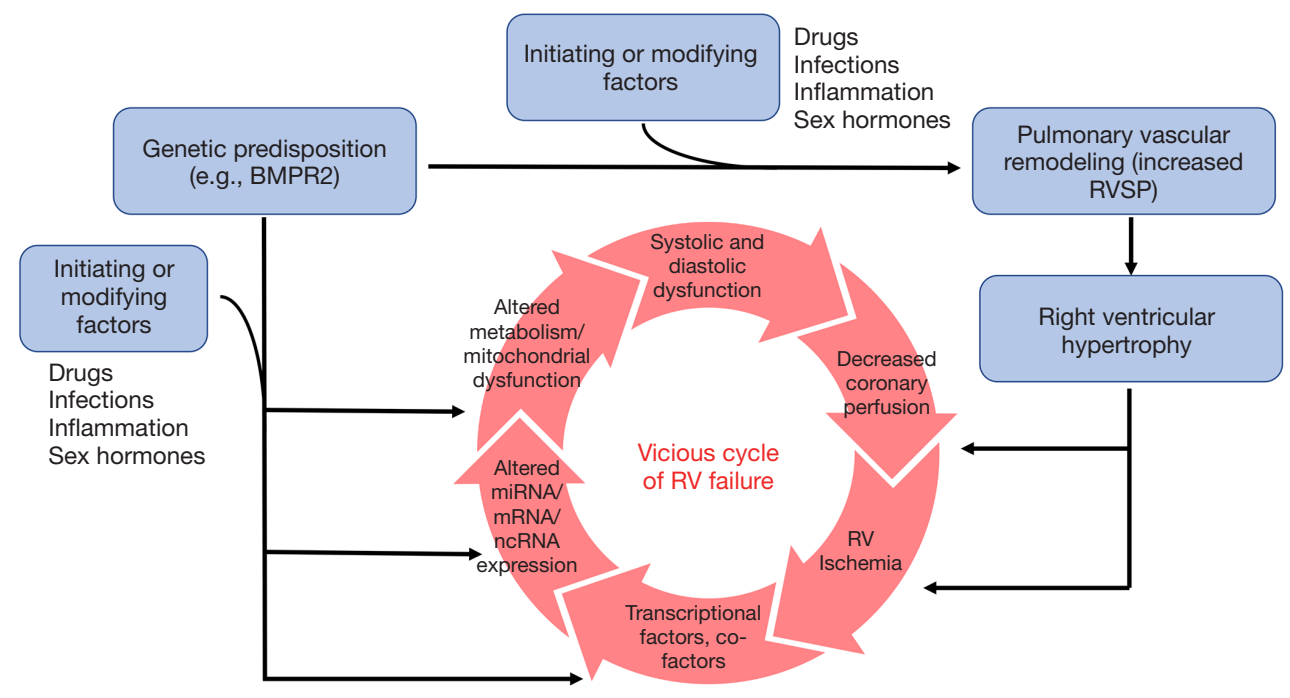

Figure 1 The vicious cycle of RV failure in PAH. In the setting of underlying genetic predispositions, initiating or modifying factors such as drugs, inflammation, infection, and/or sex hormones begin the vicious cycle of RV failure either through direct action upon the RV (via altered metabolism or transcriptional regulation), or secondarily through increased PVR and RV ischemia. RV, right ventricular; PAH, pulmonary arterial hypertension; PVR, pulmonary vascular resistance; RVSP, right ventricular systolic pressure.
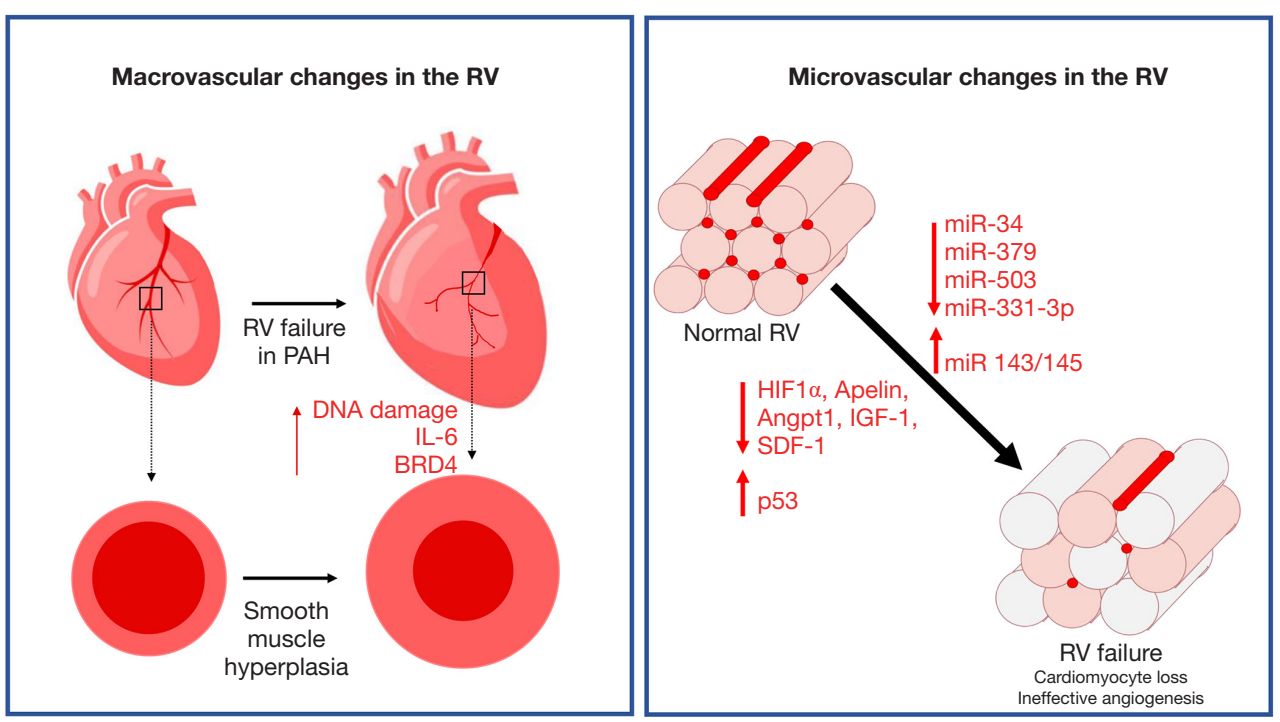

Figure 2 Schematic diagram of mechanisms underlying dysfunctional angiogenesis in the progression from adaptive RV hypertrophy to maladaptive RV failure in PAH. RV, right ventricular; PAH, pulmonary arterial hypertension.

suggesting a more causal role for microvascular dysfunction in the pathogenesis of RV failure (28). However, the translation of these pre-clinical findings to humans remains an area of ongoing investigation. A recent study of postmortem human RV from female $\mathrm{PAH}$ patients employed a stereological approach to measuring vascularity and reported an increase in total vascular length in PAH (37) without signs of hypoxia or ischemia [contradicting previous investigations $(38,39)]$. Given the multiple discrepancies between these studies (method of measurement of 
vascularity, appropriate determination of $\mathrm{RV}$ adaptation $v s$. failure in the human samples, possible sex-based effect, patient age, etc.), further work is necessary to clarify these findings.

\section{Molecular mediators of angiogenesis in RV failure}

The pathways and processes regulating angiogenesis are complex and many. Factors such as sex, age, severity of $\mathrm{PH}$, disease stage, and other inter-related processes (metabolic dysfunction, inflammation) complicate and confound clear study of angiogenic mechanisms in the RV of PAH patients. However, growing evidence from both experimental models and human samples suggests dysregulation of angiogenesis in RV failure. Experimentally, studies have suggested a genetic component to $\mathrm{RV}$ adaptation in $\mathrm{PH}$ based on differing degrees of $\mathrm{RV}$ adaptation to the same afterload in two different strains of rat (Fischer vs. Sprague Dawley) (33). Epigenetically, Reddy et al. identified microRNAs uniquely associated with RV failure that mediate increased vascular tone (miR-143/145), enhanced apoptosis (miR-34), and decreased endothelial cell proliferation (miR-379, miR-503) (40). Chouvarine et al. identified transpulmonary changes in microRNAs, one of which has been implicated in vascular smooth muscle proliferation (miR-331-3p) (41). Beyond epigenetic changes, inter- and intra-cellular signaling through transcription factors, growth factors, hormones, peptides, and immune cells have also been implicated as mediators of angiogenesis in the RV. These pathways are extensively reviewed elsewhere (42). Of these pathways, the most extensively studied parameters are those of the vascular endothelial growth factor (VEGF) pathway. In general, VEGF signaling is increased or maintained in adaptive RV hypertrophy (30,32,35), whereas VEGF signaling or receptor expression are downregulated in advanced RV failure $(29-33,43)$. The previously mentioned decrease in miR-126 noted by Potus et al. (28) was associated with increased sprouty-related EVH1 domain-containing protein 1 (SPRED-1) which resulted in decreased activation of RAF and MAPK and inhibition of the VEGF pathway. Other pathways and modifiers found to be downregulated or impaired in experimental $\mathrm{PH}$ with maladaptive $\mathrm{RV}$ remodeling and failure include hypoxia-inducible factor (HIF) $1 \alpha(29,43)$, apelin (30), angiopoietin 1 (30), insulin growth factor 1 (30), and stromal derived factor 1 (43). The study of failing Fischer rat RVs revealed a decrease in expression of several angiogenic genes such as Angpt1 and Vegfc (33). On the other hand, the HIF inhibitor p53 was found to be upregulated in one model (43). A recent study reported a surprising role of regulatory $\mathrm{T}$ cells in increasing vasoprotective mediators in human microvascular cardiac endothelial cells (44). Studies specifically studying $\mathrm{RV}$ dysfunction in the setting of experimentally induced PAH through treatment with hypoxia and Sugen-mediated VEGF inhibition identified unique alterations in a number of genes related to angiogenesis in the RV of mice with RV failure, but not controls (34). Finally, emerging mediators of angiogenesis in the RV in $\mathrm{PAH}$ include molecules with potent angiostatic properties such as endostatin that are upregulated in plasma from $\mathrm{PAH}$ patients, but have not directly been studied in the RV (45).

Ultimately, it is not clear whether directly modifying angiogenesis in the RV may be beneficial or not. Several therapeutic strategies have been associated with increased RV vascularization or increased expression of pro-angiogenic mediators. These therapies include carvedilol (46), 17ß-estradiol (47,48), genistein (49), dehydroepiandrosterone (50), exercise training (which increases RV capillarization in stable but not progressive $\mathrm{PH}$ (51), protandim (29), prostacyclin (52), cardiotrophin 1 (53), PPAR $\gamma$ agonists (34), and miR-126 mimic (28). With the exception of miR-126 mimic, which restored RV vascularization and function without affecting pulmonary vasculature, all other therapies have been tested in experimental models of $\mathrm{PH}$ where direct effects on $\mathrm{RV}$ cannot be separated from reduced afterload due to effects on pulmonary vasculature. Further studies are needed to further delineate the role and regulation of angiogenesis in RV failure (54).

\section{Sex hormones and their effect on RV function}

Cardiomyocytes and other cells found in the heart (e.g., endothelial cells and fibroblasts) contain receptors for all major sex hormones (reviewed previously) $(55,56)$. They also exhibit the machinery required for local sex hormone production and metabolism $(48,57,58)$. It therefore is not surprising that sex steroids have emerged as important modifiers of RV structure and function in PAH. This section will review the currently available knowledge of the interplay between sex steroids and RV adaptation in preclinical and clinical studies (Figure 3).

Although PAH has long been known to be a femalepredominant disease, studies have identified that females with PAH exhibit better survival than male counterparts (59-63). Females with PAH also exhibit improved RV 


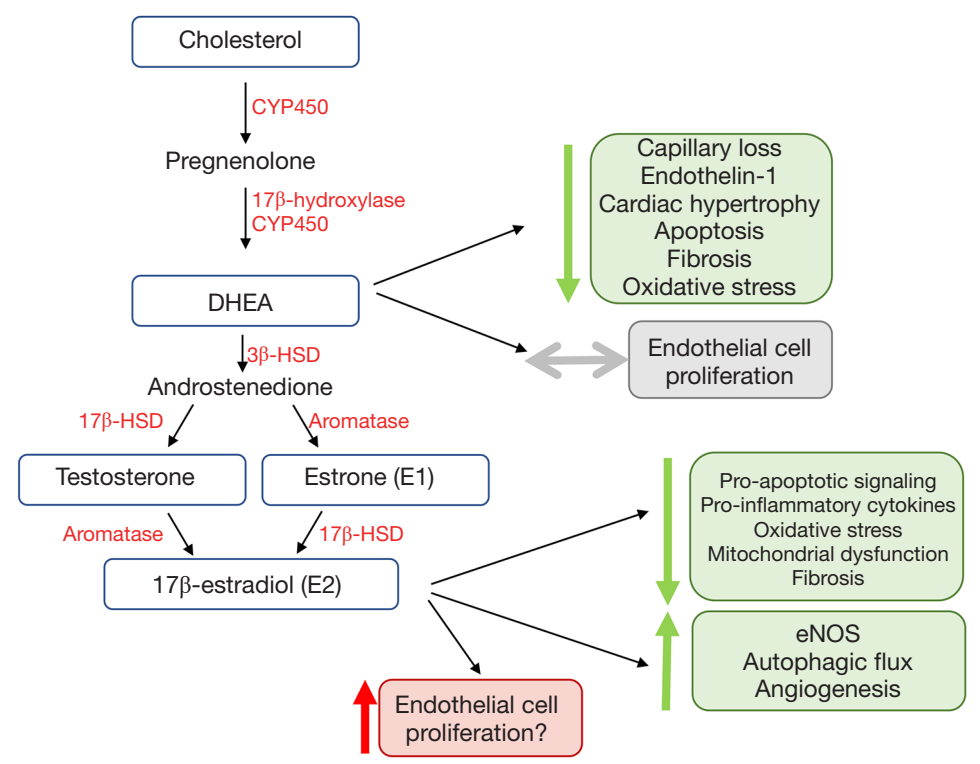

Figure 3 Sex hormone synthesis pathways with known effects of intermediates upon pulmonary vascular and RV cardiomyocyte remodeling. $\mathrm{RV}$, right ventricular.

function, even after adjustment for age, body weight, and LV function (64-66). Better RV function in females has been shown to account for a significant component of the survival advantage that has been noted in previous epidemiologic studies (63). Notably, these findings have also now been verified in other groups of patients with non-PAH types of PH (e.g., Group 2 and 3 PH) (67-69).

Several lines of evidence indicate that sex hormones may, in part, account for the sex-specific differences noted in RV function. In healthy individuals without $\mathrm{PAH}$ in the MESA-RV cohort, post-menopausal hormone therapy users exhibited higher RV ejection fraction (RVEF) than non-users (70). In hormone therapy users, plasma levels of $17 \beta$-estradiol (E2) correlated with higher RVEF and lower RV end-diastolic volumes. Other studies of the MESARV cohort have found that higher DHEA plasma levels are associated with lower RVEF, higher RV stroke volume, and larger RV mass/volume (70). Finally, studies have demonstrated that single nucleotide variants that modulate the function of estrogen metabolism such as cytochrome P450 1B1 (CYP1B1) and androgen receptor (AR) are associated with changes in RV structure/function in normal patients, suggesting a direct role for sex-hormone mediated modification of RV size/function (71).

The roles of estrogen and DHEA in modifying RV function have been replicated indirectly in a cohort of PAH patients as well. Females younger than age 45 exhibited higher cardiac index than male counterparts (66). However, this difference dissipated after 45 years of age, suggesting that sex hormones are a potential modifier of RV adaptation in PAH. Additionally, in post-menopausal women with PAH, lower DHEA levels were associated with increased RV dilation and worse function by echocardiogram (72). Given the dual roles of sex hormones upon myocardial and pulmonary vascular function, though, these studies cannot distinguish whether the observed associations were due to primary effects on the RV as opposed to indirect changes as a result of modulation of $\mathrm{RV}$ afterload.

Several studies have now investigated the therapeutic potential of modulating the sex hormone axis (Figure 3) in regulating $\mathrm{RV}$ function in models of $\mathrm{PAH}$. Interestingly, while estrogen E2 or its metabolites are thought to promote adverse pulmonary vascular remodeling (73), E2 has been shown to exhibit RV-protective effects in vivo. Through hormone depletion and repletion studies in a rat model of Sugen/hypoxia, Frump et al. demonstrated that E2 attenuates RV hypertrophy, improves cardiac index, and enhances exercise capacity (48). The presence of E2 results in decreased RV apoptotic signaling, pro-inflammatory cytokine expression, oxidative stress, and mitochondrial dysfunction (48). Additionally, E2 attenuated decreases in pro-angiogenic and pro-contractile expression of apelin, 
suggesting a role for E2 in angiogenesis (48). Importantly, protective effects of $\mathrm{E} 2$ were noted in ovariectomized female rats as well as in male rats. In a follow-up study in SuHx rats, E2 attenuated RV dysfunction induced by a bout of acute strenuous exercise; these effects were accompanied by increased eNOS activation and enhanced autophagic flux in the RV (74). This study also demonstrated anti-fibrotic effects of E2. Anti-fibrotic effects were also observed in the SuHx-PH mouse model (75), even though it should be noted that this model only exhibits mild RV dysfunction (54). The same group of investigators also reported beneficial effects on mitochondrial function in the RV with E2 treatment (76). A study performed in the monocrotaline rat model suggested pro-angiogenic effects of E2 (47). While that study suggested estrogen receptor $\beta$ as a mediator of protective $\mathrm{E} 2$ effects in the $\mathrm{RV}$, the previously mentioned study in SuHx-PH rats (48) implicated estrogen receptor $\alpha$ as a mediator of E2 protection. The reasons for this discrepancy are unclear, but may include differences between models, sex-specific effects or off-target effects of pharmacological inhibitors and activators. In addition, E2 also affects mechanical properties of the pulmonary vasculature which in turn could affect $R V$ structure and performance. In particular, E2 can increase both proximal as well as distal PA compliance, and, at least when given exogenously, also attenuate PA remodeling $(75,77,78)$. It is currently unknown if E2's RV-protective effects are mediated by direct effects on RV-specific cell types or by more indirect effects resulting from reducing RV afterload. Studies employing PAB and investigating E2 signaling in RV-specific cell types (cardiomyocytes, endothelial cells and fibroblasts) will address this knowledge gap.

In addition to estrogen, testosterone and DHEA signaling have also been studied in the RV. While testosterone was associated with worse RV function and fibrosis in a pulmonary banding model (79), DHEA was found to attenuate RV capillary rarefaction, apoptosis, fibrosis, and oxidative stress in Sugen/hypoxia treated rats. This was at least partially mediated by reducing expression/ activity of Rho kinases, STAT3, and NFATc3 (50). Direct study of cardiomyocytes in vitro has demonstrated that DHEA reduces endothelin-1 induced hypertrophy and natriuretic peptide expression (80). With aldosterone or corticosteroid stimulation, DHEA decreases T-type calcium channel expression and exhibits anti-hypertrophic/ chronotropic effects (81). Unlike E2, however, DHEA has not been associated with adverse pulmonary vascular remodeling, making this an attractive target for hormone- based therapies for RV failure.

While no clinical studies to date have directly used hormone-based therapies to improve RV failure in PAH, there is a growing interest in these pathways given preclinical benefit from E2 and DHEA. In particular, there are two trials currently investigating the effect of estrogen inhibition on PAH development (NCT03229499, NCT03528902), based on the known association between E2 levels and adverse pulmonary vascular remodeling $(72,73,82)$. Given concerns regarding potential direct detrimental effects on RV function (83), and despite relatively neutral effects upon the RV in pilot studies $(84,85)$, both ongoing trials are closely monitoring RV function in their participants. Ultimately, due to E2's pleiotropic effects, more specific or downstream approaches may be necessary to maximize the benefits and limit the harms of modulating estrogen therapies in PAH. Therapy with DHEA may be a more straightforward target based on its beneficial effect upon RV function in the absence of detrimental effects upon pulmonary vasculature. A study investigating DHEA supplementation in $\mathrm{PAH}$ is currently ongoing and will assess RV function and structure by cardiac MRI (NCT03648385).

\section{Metabolic derangements in RV hypertrophy, dilation and failure}

Cellular metabolism comprises a ubiquitous set of pathways that continually maintain cellular homeostasis through modulation of energy production, synthesis of components, breakdown of waste, and ultimately cell survival. These pathways are particularly relevant in high energy utilizing tissues such as the heart. Despite the known differences in embryologic origin, baseline expression, and loading conditions of the right and left ventricle $(5,7,86,87)$, the majority of studies investigating RV metabolism are based on metabolic investigations in the LV (88). Under basal conditions, the RV generates ATP primarily from fatty acids $(70 \%)$ with a smaller percentage from uncoupled glycolysis or lactate utilization (89). However, in various situations, the myocardium is able to generate ATP from any of a number of sources including fatty acids, glucose, lactate, ketones, and amino acids, demonstrating metabolic plasticity (90-93). Stresses such as increased load on the RV or ischemia can drive changes in the uptake, generation, transport, storage and utilization of preferred substrate for energy generation (5).

Studies of pulmonary vascular endothelial cells from patients with $\mathrm{PAH}$ have identified metabolic shifts in $\mathrm{PAH}$ 


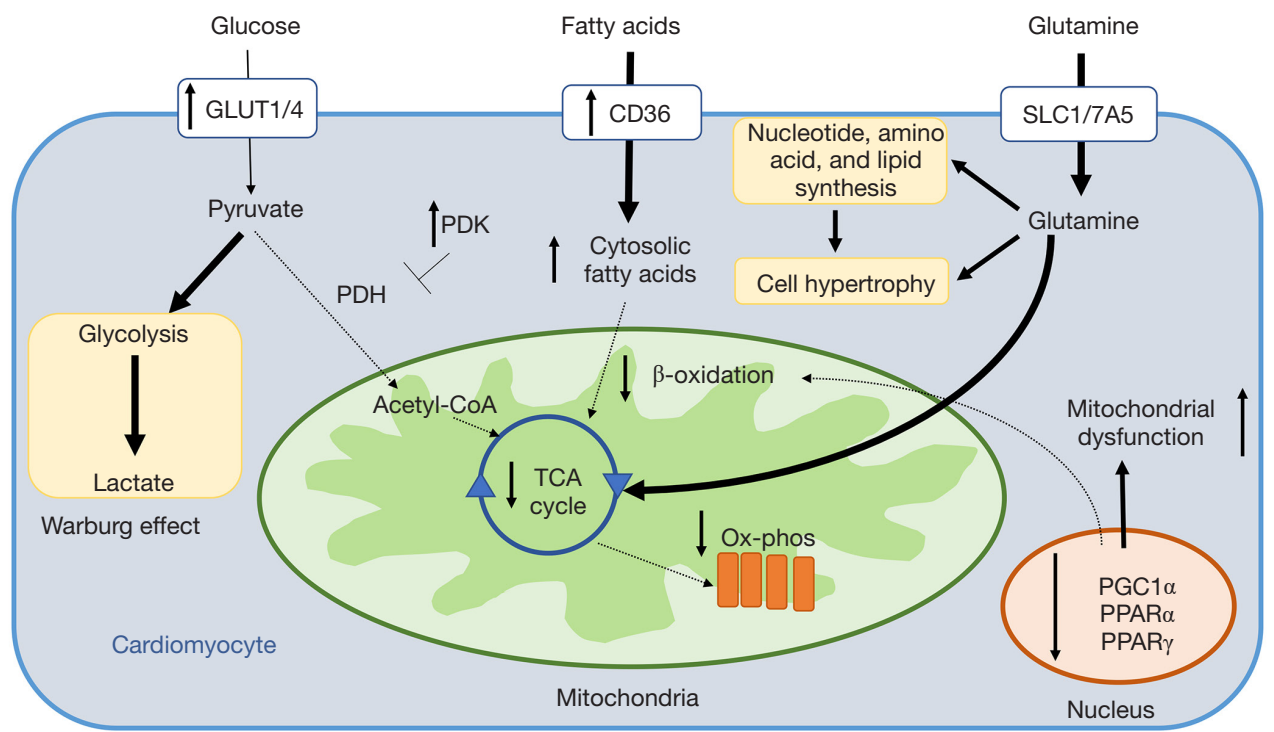

Figure 4 Summary of metabolic derangements identified in RV cardiomyocytes in PAH. Solid arrows denote pathways increased in PAH, and dashed arrows represent pathways decreased in PAH. RV, right ventricular; PAH, pulmonary arterial hypertension.

that mirror metabolic changes in malignancy (7). In PAH, these metabolic shifts in carrdiovascular cells include an increased preference for aerobic glycolysis (known as the Warburg effect) (94), impaired mitochondrial respiration due to decreased fatty acid oxidation $(95,96)$, and increased utilization of glutamine in the Krebs cycle for biosynthesis and proliferation (97). The mechanisms by which each of these pathways affects myocardial function, and potential avenues for therapeutic intervention, are discussed below (Figure 4).

\section{Mitochondrial dysfunction in the RV in PAH}

Mitochondria are the intracellular site for many important metabolic pathways including oxidative phosphorylation, Krebs cycle, $\beta$ oxidation of fatty acids, calcium handling, free radical handling, and heme synthesis. It is thus not surprising that mitochondrial dysfunction is thought to play a central role in PAHrelated metabolic reprogramming $(98,99)$. Mitochondrial morphology is intimately connected with the overall metabolic state of a cell (100). This is particularly true in a high energy utilizing cell such as the cardiomyocyte where mitochondria account for nearly $90 \%$ of the ATP generation and $30 \%$ of the overall cell mass (101).

Mitochondrial dysfunction has been shown to play a central role in the progression of left heart failure (102).
However, preclinical studies of RV failure in the setting of PAH have also demonstrated a decrease in intact mitochondria $(31,34,103,104)$. Legchenko et al. (34), showed that Sugen/hypoxia exposed rats developed RV hypertrophy and dilation 6 weeks after the end of hypoxia. By applying comprehensive electron microscopy studies, Legchenko et al. demonstrated increased variability in mitochondrial size, mitochondrial disarray, decreased mean mitochondrial diameter, and an increased number of autophagosomes near mitochondria, all suggesting dysregulation of mitochondrial morphology and function (mito dynamics) (34).

Importantly, the detrimental structural changes and dysfunction of mitochondria are associated with decreased expression of metabolic master regulators such as PPAR $\gamma$ (105), PPAR $\gamma$ coactivator (PGC1 $\alpha$ ) (103), and $\operatorname{PPAR} \alpha$ (103). These three metabolic master regulators have key functions in myocardial function, particularly in the setting of RV pressure overload associated with PAH. In particular, targeted deletion of PPAR $\gamma$ in cardiomyocytes in mice, in the absence of $\mathrm{PAH}$, led to biventricular systolic dysfunction, suggesting a direct role for modulating cardiomyopathy even in the absence of an increased RV afterload (34).

The PPAR agonist pioglitazone reverses pulmonary arterial hypertension and prevents right heart failure in the $\mathrm{SuHx}$ rat model via fatty acid oxidation and induction of key genes such as CPT1b and FABP4 (34). The major 
transcriptional epigenetic pathogenic findings of this study in SuHx rats could be recapitulated in human end-stage PAH (34): (I) in the pressure-overloaded failing RV (miR197 and miR-146b up-regulated; CPT1B and FABP4 downregulated), (II) in peripheral pulmonary arteries (miR$146 \mathrm{~b}$ up-regulated, miR-133b down-regulated), and (III) in plexiform vasculopathy (miR-133b up-regulated, miR-146b down-regulated) (34).

The mechanisms that lead to decreased mitochondrial mass are incompletely understood, but have been thought to be related to imbalances in mitochondrial fission/fusion and mitophagy $(99,106,107)$. Mitochondria are dynamic organelles that organize in networks to coordinate cellwide metabolic function (98). As such, mitochondria exist in a constant state of flux. They undergo fission and fusion as they adapt to the needs of the cell, with surplus or mitochondria undergoing mitophagy to maintain the mitochondrial network integrity. Dynamin-like GTPases knowns as mitofusins (MFN1 and MFN2) mediate fusion of mitochondria. Conversely, dynamin-related proteins (Drp1) complexes with mitochondrial fission protein 1 (Fis1) on the outer membrane of mitochondria to regulate fission. Studies of human pulmonary artery (PA) smooth muscle cells from patients with PAH have demonstrated increased fragmentation of mitochondria and increased mRNA expression of fissiogenic molecules (Drp1, Fis1). The presence of activated Drp1 has also been demonstrated in the pulmonary vasculature in fixed tissue sections of patients with PAH (108). Pre-clinical models of PAH using monocrotaline induced vascular damage have also confirmed increased expression of Drp1 in the right ventricle of rats with PAH (108).

\section{Glycolytic patbways and pyruvate}

While the RV normally preferentially metabolizes free fatty acids to generate ATP through oxidative phosphorylation (89), ischemia and pressure afterload on the RV result in a shift from fatty acid oxidation towards increased reliance on glucose for ATP generation $(109,110)$. Specifically, glucose utilization largely shifts towards the glycolytic pathway and away from the Krebs cycle (111). This shift occurs despite the adequate availability of oxygen to undergo oxidative phosphorylation, a phenomenon known as the Warburg effect, and ultimately decreases the efficiency of ATP generation by reducing utilization of mitochondrial oxidative metabolic pathways. Both pre-clinical and clinical studies have demonstrated the importance of pyruvate dehydrogenase kinase (PDK) in mediating the shift towards aerobic glycolysis in PAH $(112,113)$. PDK is a key inhibitor of pyruvate dehydrogenase, and therefore an inhibitor of glucose oxidation. Studies have shown a marked increase in the expression of PDK isoforms in patients with $\mathrm{PAH}$, with the predominant cardiac isoforms consisting of PDK2 and PDK4. Preferential switch towards glycolysis is associated with decreased RV contractility. In pre-clinical models, pharmacologic inhibition of PDK results in improved RV contractility (Figure 5) (112). Recently, in a clinical study of patients with $\mathrm{PAH}$ without clinical improvement on standard therapies, pharmacologic inhibition of PDK with a small molecular inhibitor, dichloroacetate (DCA), resulted in decreases in mean PA pressure, decrease in PVR, and increase in cardiac output (CO). Interestingly, response to DCA was stratified by the presence or absence of common genetic variants in two genes known to alter baseline PDK activity independently, sirtuin 3 and uncoupled protein 2. Beyond altering PDK activity, recent studies have also shown that sirtuin 3 may itself be a master regulator of metabolism in $\mathrm{PAH}$, suggesting that a subset of patients with PAH may be more likely to derive benefit from metabolic therapies $(97,114)$. However, considering both the subset of patients more likely to respond to therapy as well as identification of potential severe neurotoxicity as a result of PDK inhibition by DCA $(115,116)$, the ultimate translatability of PDK inhibition may require precision medicine approaches to define the subset of patients most likely to benefit and least likely to experience side effects.

\section{Dysfunctional fatty acid metabolism and lipotoxicity}

Previous studies have also consistently found that the RV of patients with $\mathrm{PAH}$ demonstrates significant decreases in fatty acid oxidation compared to patients without $\mathrm{PAH}$ $(5,7)$. Other studies have demonstrated an increase in lipid accumulation in the RV myocardium of patients with $\mathrm{PAH}$ $(12,95)$. While the mechanisms underlying this observation are incompletely understood, multiple mechanisms have been identified that contribute both to decreased fatty acid oxidation and cytoplasmic lipid accumulation. Impairment of fatty acid oxidation, concomitant with increased fatty acid uptake, enable the production of toxic intermediates such as ceramide, palmitate, and medium and long chain fatty acids $(12,91,96,117)$. The above intermediates most likely lead to lipotoxic cardiomyopathy, for example, via 
excessive development of reactive oxygen species and cell apoptosis (118).

Derangements in fatty acid oxidation and toxic lipid accumulation are thought to occur as a result of multiple mechanisms. The first is an increase in the uptake of fatty acids into the myocardium. Fatty acid binding proteins and CD36 are thought to be the primary receptors responsible for transporting fatty acids into the cytoplasm of cells, with CD36 being responsible for $\sim 60 \%$ of fatty acid uptake $(119,120)$. Pre-clinical studies in a model of BMPR2 mutation related $\mathrm{PAH}$ have demonstrated an increase in the expression of CD36 in the RV of mice that develop PAH (12). Additionally, increased circulating levels of heart-specific fatty acid binding protein have been found to be an independent predictor of adverse outcomes in patients with chronic thromboembolic pulmonary hypertension $(\mathrm{PH})(121)$.

The second mechanism thought to contribute to this accumulation of lipids in cardiomyocytes is the finding that the RV in PAH is characterized by a decrease in mitochondrial utilization of fatty acids compared to healthy controls $(5,95,122)$. This phenomenon, while incompletely understood, is postulated to be regulated transcriptionally and metabolically. Transcriptional regulation occurs through the noted downregulation of key modulators and inducers of mitochondrial fatty acid oxidation, PPAR $\gamma$ and PGC1 $\alpha$ (103). Metabolic regulation has been proposed to occur through the Randle Cycle $(5,123)$, a metabolic process in which glucose and fatty acids counter-regulate each other by directly competing as substrates for ATP generation within a given cell. While previous studies have suggested that a further shift away from fatty acid oxidation towards glucose oxidation through the Randle cycle will reduce oxygen consumption by $\sim 12 \%$ per ATP molecule generated (5), recent studies suggest that a shift from fatty acid to glucose oxidation ultimately results in less efficient ATP production and ultimately promotes hibernation of myocardium (34). The mechanical complications of hibernating myocardium have been reviewed elsewhere (22). A recent study by Chouvarine $e t$ al. has also demonstrated accumulation of dicarboxylic acids and acylcarnitines trans-RV gradients, suggesting a block in $\beta$-fatty acid oxidation (41). The identified trans-RV and transpulmonary metabolite gradients also correlate with hemodynamics, further supporting a functional consequence of the identified metabolic changes

Thus, there are currently alternative approaches aimed directly at addressing the deficit in fatty acid oxidation with a goal of normalizing the RV metabolic pattern. One approach has involved the use of therapies aimed at activating PPAR $\gamma$, a key modulator of fatty acid oxidation. Pre-clinical trials investigating the efficacy of PPAR $\gamma$ agonists have demonstrated that increasing fatty acid oxidation can prevent the development of $\mathrm{RV}$ failure in a model of endothelial injury and hypoxia mediated PAH and RV failure (Figure 5) (34). Another approach that is currently undergoing pre-clinical and clinical investigation is the use of metformin to reverse deficits in fatty acid oxidation (Figure 5). Multiple preclinical models of both $\mathrm{PAH}$ and $\mathrm{PH}$ due to heart failure have demonstrated a potential beneficial role for metformin in both decreases in RV lipid accumulation as well as reversal of pulmonary vascular remodeling $(96,124,125)$. Clinical trials are currently ongoing that will be directly assess the potential benefit of metformin on both clinical outcomes and RV function (NCT 01884051 and NCT03617458). Metformin's function is thought to be pleiotropic, but thought to involve at least the activation of AMP kinase (and downstream decrease in fatty acid synthesis and increase in insulin sensitivity) as well as non-AMPK mediated inhibition of adenylyl cyclase to ultimately promote decreased gluconeogenesis and increased glycolytic activity $(96,126,127)$. Finally, although limited to a single center, a clinical study in a select population of patients with $\beta$-thalassemia and $\mathrm{PH}$ demonstrated that oral administration of L-carnitine significantly reduced pulmonary pressures (128). While the mechanisms underlying this phenomenon are not clear, L-carnitine serves as a shuttle for long-chain fatty acids to be transported to the mitochondria to undergo $\beta$ oxidation, again suggesting that restoring fatty acid oxidation may be valuable.

\section{Insulin resistance and dyslipidemia in PAH-related RV dysfunction}

Although insulin resistance is known to be a primary contributor systemic arteriovascular disease, studies have also shown a higher than expected prevalence of insulin resistance in patients with PAH (129-134). The known alterations in glucose and fatty acid oxidation ultimately contribute to mitochondrial dysfunction, a key driver of insulin resistance in multiple cell types (135). In addition to stimulating increased glucose uptake and fatty acid oxidation, insulin plays an important role of modulating lipid homeostasis by modulating lipolysis and free fatty acid delivery between adipose and liver tissues (136). While 

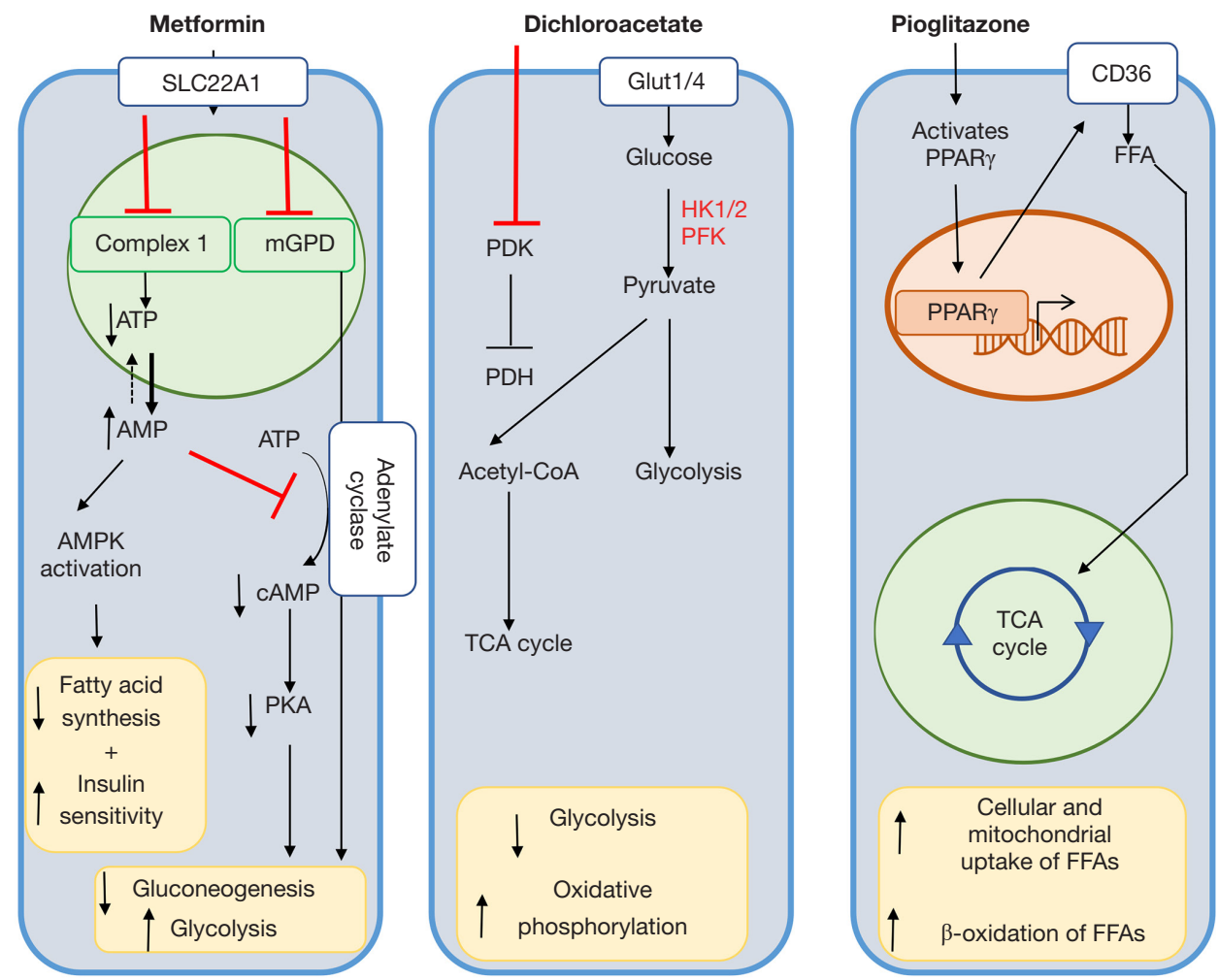

Figure 5 Main mechanisms of action of metformin, dichloroacetate (DCA), and PPAR $\gamma$ agonist pioglitazone in cardiomyocytes in the prevention and/or treatment of RV failure in PAH. RV, right ventricular; PAH, pulmonary arterial hypertension. SLC22A1, organic cation transporter; mGPD, mitochondrial glycerophosphate dehydrogenase; AMPK, 5' AMP-activated protein kinase; ATP, adenosine triphosphate; cAMP, cyclic adenosine monophosphate; PKA, protein kinase A; PDK, pyruvate dehydrogenase kinase; PDH, pyruvate dehydrogenase; HK 1/2, hexokinase 1/2; PFK, phosphofructokinase; Glut1/4, glucose transporter 1/4; FFA, free fatty acid; TCA, tricarboxylic acid; PPAR, peroxisome proliferator-activated receptor.

insulin resistance has been shown to be a contributor to pathologic pulmonary vascular remodeling in multiple pre-clinical models of PAH $(129,130,133,134,137)$, recent studies have also demonstrated a key role for insulin in altering RV function in humans as well. In vitro, recent studies have demonstrated a causal role for BMPR2 in maintaining insulin signaling and glucose homeostasis in cardiomyocyte-like cells (138). Studies in human RV and $\mathrm{LV}$ also suggest that the $\mathrm{RV}$ may be more prone to changes in insulin-related signaling. RNA sequencing analysis of healthy human RV and LV demonstrated an increase in transcripts associated with insulin signaling in the RV (139). Additionally, patients with diabetes but without PAH (and therefore no significant afterload) consistently demonstrate decreases in indices of $\mathrm{RV}$ function non-invasively (140-142). Finally, the presence of metabolic syndrome, and not obesity alone, is associated with a load-dependent decrease in RV function, suggesting a loss of contractile reserve in the setting of insulin resistance (143). Most recently, Mey et al. have utilized a hyperglycemic clamp in patients with $\mathrm{PAH}$ and controls to demonstrate global alterations in glucose homeostasis with a reduced response of insulin response to hyperglycemia (144). More importantly, their work suggested compartmental changes in insulin sensitivity, with increased insulin sensitivity in the skeletal muscle despite a decreased insulin response to hyperglycemia. While their study cannot directly comment on myocardial insulin sensitivity, their study corroborates previous studies confirming an important and direct role for insulin signaling in the pathogenesis of PAH $(129,131,144)$.

\section{Glutaminolysis}

It is known that both the pulmonary endothelium and right 
ventricle shift towards increased utilization of glutamine in patients with PAH (97). Glutamine is transported into the cell and converted into $\alpha$-ketoglutarate by glutamate dehydrogenase. $\alpha$-ketoglutarate is then fed into the Krebs cycle where its byproducts contribute to synthesis of amino acids, purines, pyrimidines, fatty acids, and sterols. While these byproducts are thought to contribute to increased cell growth and proliferation in cancer cells (145), its role in post-mitotic tissues such as the RV are less understood. In the pre-clinical model of monocrotaline-induced PAH and $\mathrm{RV}$ failure in rats, increased utilization of glutamine as well as increased expression of glutamine transporters was identified in the RV of rodents that developed PAH (31). Immunostains of post-mortem RV from patients with $\mathrm{PAH}$ also suggested an increase in sarcolemmal glutamine transporter expression, suggesting that glutaminolysis may be an important therapeutic target in RV failure due to PAH. Given the paucity of studies investigating this mechanism of altered metabolism in the RV, however, future studies are necessary to better elucidate the pathogenic role of glutaminolysis in RV failure.

\section{Limitations and future approaches to understanding of molecular mechanisms underlying human RV failure}

Pathophysiologic mechanisms contributing to RV failure in the setting of PAH have largely relied on pre-clinical studies in which careful manipulation, both genetic and therapeutic, are possible to tease out potential mechanisms. As reviewed by Stenmark et al., though, no current animal model of PAH perfectly recapitulates all features of the human disease (146). Additionally, this special issue also extensively discusses the strengths and weaknesses of various animal models of RV failure elsewhere (147). The study of RV failure in human subjects at the molecular level is inherently limited by the availability and quality of tissues available from patients, often post-mortem or at end stage. Additionally, modalities of study are often limited by methods of tissue preservation that have been applied such as formalin fixation and paraffin embedding. While modalities such as cardiac MRI have significant improved resolution in the measurement of RV size and function (63), specific studies of molecular pathways or targets are inherently limited in current non-invasive assessments of the RV in PAH. The role of imaging in RV failure and overall prognosis in $\mathrm{PH}$ is discussed elsewhere in this special issue (148-150).

\section{Induced pluripotent stem (iPS) cells as an alternative to buman tissue}

While many previous studies have utilized isolated endothelial or PA smooth muscle cells for detailed in vitro studies, similar approaches are limited for study of the myocardium. In particular, cardiomyocytes are generally post-mitotic cells with very few studies successfully isolating and studying the myocytes themselves from human patients (8). The seminal finding by Takahashi and Yamanaka in 2006 that transfection of a defined set of transcription factors can convert differentiated cells into embryonic-like stem cells [induced pluripotent stem (iPS) cells] paved the way for tissue specific generation of various cell types from patient samples through transcription factor mediated generation of iPS cells. Previous groups have utilized this approach to begin to study the effect of known PAH-causing mutations in the BMPR2 gene upon endothelial and smooth muscle function (151-153). With significant advances in methods for generation of iPS derived cardiomyocytes (154), the pathogenesis of RV cardiomyopathy in the setting of either known mutations associated with PAH (i.e., BMPR2) or known patient populations who develop $\mathrm{RV}$ failure out of proportion to the degree of PH (i.e., systemic sclerosis) can be studied. With studies now demonstrating functional and molecular analyses in both single cells and engineered heart tissue constructs (155-157), as well as other studies beginning to identify protocols to specifically differentiate RV vs. LV cardiomyocytes (158), the use of iPS derived cardiomyocyte may shed light on to primary pathologic changes that occur in the myocardium in patients with $\mathrm{PAH}$ without the confounding variable of afterload $(40,154,159)$.

\section{Lessons learned from non-PAH related $R V$ failure}

While the current review has focused on mechanisms underlying $\mathrm{RV}$ failure in $\mathrm{PAH}$, most patients with RV dysfunction suffer from $\mathrm{PH}$ due to other causes. Given the larger number of these group PH patients, directed study of these populations may provide further insight into the pathogenesis of RV failure in PAH as well. Indeed, at least a subset of patients with $\mathrm{PH}$ due to left heart disease (PH-LHD) display shared genetic architecture with $\mathrm{PAH}$ patients (160). Additionally, it is now recognized that a subset of patients with hemodynamics consistent with $\mathrm{PAH}$ at rest actually have occult diastolic dysfunction and resulting PH-LHD upon provocative challenge with 
saline $(161,162)$. Taken together there may, in fact, be some mechanistic overlap in the pathogenesis of RV failure among various groups of $\mathrm{PH}$.

Similar to PAH, animal models of PH-LHD have also identified RV dysfunction as an early manifestation of disease (163). Exploiting common genetic variability among available mouse strains to identify genetically similar mice that were susceptible and resistant to high fat diet induced PH-LHD (164), a clearance receptor for natriuretic peptides (NPRC) was found to be the most differentially expressed gene in the RV of mice that developed PH-LHD. Natriuretic peptide levels also correlated with development of RV failure and PAH in a Sugen hypoxia model, and decreased in response to pioglitazone treatment (34). Finally, clinical studies have also demonstrated increased PVR in both pre-clinical and clinical models inversely correlated with levels of natriuretic peptides (165-168), altogether suggesting that natriuretic peptides and related pathways may be potential therapeutic targets in RV failure in PAH. Future studies are necessary to directly test this hypothesis, however.

\section{Conclusions}

$\mathrm{RV}$ failure continues to be the primary cause of morbidity and mortality in patients with PAH. In part due to fundamental differences between the LV and RV, and in part due to limitations in access to and ability to study human RV directly, the pathogenesis of maladaptive RV remodeling and resulting heart failure is incompletely understood. However, based on the breadth of pre-clinical and clinical studies to date, dysfunctional angiogenesis, sex hormone related biology, and fundamental shifts in cellular metabolism appear to play primary roles in the transition from adaptive to maladaptive remodeling of the RV. As preclinical studies continue to unravel the causal pathways that contribute to RV dysfunction in the setting of PAH, we look forward to future studies directly assessing the contributions of these pathways to RV failure in humans through both mechanistic and therapeutic studies.

\section{Acknowledgments}

Funding: NIH R01-HL122417 (ARH), NIH T32HL007411 (VA), Vanderbilt Chancellor's Faculty Fellow Award (ARH), Team Phenomenal Hope Foundation Grant
(VA), NIH R01-HL144727-01A1 (TL), VA Merit Review Award 2 I01 BX002042 (TL, German Research Foundation DFG HA4348/2-2 and HA4348/6-2 (GH), and Federal Ministry of Education and Research BMBF ViP+ program03VP08053; BMBF 01KC2001B (GH).

\section{Footnote}

Provenance and Peer Review: This article was commissioned by the Guest Editors (Martin Koestenberger, HarmJan Bogaard and Georg Hansmann) for the series "Right Ventricular Dysfunction" published in Cardiovascular Diagnosis and Therapy. The article was sent for external peer review organized by the Editor-in-Chief and the editorial office.

Conflicts of Interest: All authors have completed the ICMJE uniform disclosure form (available at http://dx. doi. org/10. 21037/cdt-20-404). The series "Right Ventricular Dysfunction" was commissioned by the editorial office without any funding or sponsorship. GH served as the unpaid Guest Editors of the series. TL reports personal fees from Bayer, Inc., outside the submitted work. GH reports patent "Compositions and method for treatment of pulmonary hypertension", 12/2009 USPTO application no. 1289344, Stanford University (Inventors: Georg Hansmann, Roham T. Zamanian, Marlene Rabinovitch). ARH reports personal fees from Actelion, personal fees from Bayer, personal fees from Complexa, personal fees from PHPrecisionMed, personal fees from united therapeutics, outside the submitted work. The author has no other conflicts of interest to declare.

Ethical Statement: The authors are accountable for all aspects of the work in ensuring that questions related to the accuracy or integrity of any part of the work are appropriately investigated and resolved.

Open Access Statement: This is an Open Access article distributed in accordance with the Creative Commons Attribution-NonCommercial-NoDerivs 4.0 International License (CC BY-NC-ND 4.0), which permits the noncommercial replication and distribution of the article with the strict proviso that no changes or edits are made and the original work is properly cited (including links to both the formal publication through the relevant DOI and the license). 
See: https://creativecommons.org/licenses/by-nc-nd/4.0/.

\section{References}

1. Humbert M, Lau EMT, Montani D, et al. Advances in therapeutic interventions for patients with pulmonary arterial hypertension. Circulation 2014;130:2189-208.

2. Inampudi C, Hemnes AR, Briasoulis A. Approach to a patient with pulmonary hypertension. J Geriatr Cardiol 2019;16:478-81.

3. Hoeper MM, McLaughlin VV, Dalaan AM, et al. Treatment of pulmonary hypertension. Lancet Respir Med 2016;4:323-36.

4. Haddad F, Hunt SA, Rosenthal DN, et al. Right ventricular function in cardiovascular disease, part I: anatomy, physiology, aging, and functional assessment of the right ventricle. Circulation 2008;117:1436-48.

5. Archer SL, Fang YH, Ryan JJ, et al. Metabolism and bioenergetics in the right ventricle and pulmonary vasculature in pulmonary hypertension. Pulm Circ 2013;3:144-52.

6. van de Veerdonk MC, Kind T, Marcus JT, et al. Progressive right ventricular dysfunction in patients with pulmonary arterial hypertension responding to therapy. J Am Coll Cardiol 2011;58:2511-9.

7. Ryan JJ, Archer SL. Emerging concepts in the molecular basis of pulmonary arterial hypertension. Part I: Metabolic plasticity and mitochondrial dynamics in the pulmonary circulation and right ventricle in pulmonary arterial hypertension. Circulation 2015;131:1691-702.

8. Hsu S, Kokkonen-Simon KM, Kirk JA, et al. Right ventricular myofilament functional differences in humans with systemic sclerosis-associated versus idiopathic pulmonary arterial hypertension. Circulation 2018;137:2360-70.

9. van der Bruggen CE, Happé CM, Dorfmüller P, et al. Bone morphogenetic protein receptor type 2 mutation in pulmonary arterial hypertension: a view on the right ventricle. Circulation 2016;133:1747-60.

10. Manders E, Bogaard HJ, Handoko ML, et al. Contractile dysfunction of left ventricular cardiomyocytes in patients with pulmonary arterial hypertension. J Am Coll Cardiol 2014;64:28-37.

11. Morrell NW, Aldred MA, Chung WK, et al. Genetics and genomics of pulmonary arterial hypertension. Eur Respir J 2019;53:1801899.

12. Talati MH, Brittain EL, Fessel JP, et al. Mechanisms of lipid accumulation in the bone morphogenetic protein receptor type 2 mutant right ventricle. Am J Respir Crit Care Med 2016;194:719-28.

13. van der Bruggen CEE, Tedford RJ, Handoko ML, et al. RV pressure overload: from hypertrophy to failure. Cardiovasc Res 2017;113:1423-32.

14. Viswanathan G, Mamazhakypov A, Schermuly RT, et al. The role of $g$ protein-coupled receptors in the right ventricle in pulmonary hypertension. Front Cardiovasc Med 2018;5:179.

15. Emanuel R, Chichra A, Patel N, et al. Neurohormonal modulation as therapeutic avenue for right ventricular dysfunction in pulmonary artery hypertension: till the dawn, waiting. Ann Transl Med 2018;6:301.

16. Ware JA, Simons M. Angiogenesis in ischemic heart disease. Nat Med 1997;3:158-64.

17. Oka T, Akazawa H, Naito AT, et al. Angiogenesis and cardiac hypertrophy: maintenance of cardiac function and causative roles in heart failure. Circ Res 2014;114:565-71.

18. Shiojima I, Sato K, Izumiya Y, et al. Disruption of coordinated cardiac hypertrophy and angiogenesis contributes to the transition to heart failure. J Clin Invest 2005; 115:2108-18.

19. Vonk Noordegraaf A, Westerhof BE, Westerhof N. The Relationship Between the Right Ventricle and its Load in Pulmonary Hypertension. J Am Coll Cardiol 2017;69:236-43.

20. Vonk Noordegraaf A, Chin KM, Haddad F, et al. Pathophysiology of the right ventricle and of the pulmonary circulation in pulmonary hypertension: an update. Eur Respir J 2019;53:1801900.

21. Zong P, Tune JD, Downey HF. Mechanisms of oxygen demand/supply balance in the right ventricle. Exp Biol Med (Maywood) 2005;230:507-19.

22. Kloner RA. Stunned and hibernating myocardium: where are we nearly 4 decades later? J Am Heart Assoc 2020;9:e015502.

23. van Wolferen SA, Marcus JT, Westerhof N, et al. Right coronary artery flow impairment in patients with pulmonary hypertension. Eur Heart J 2008;29:120-7.

24. Vogel-Claussen J, Skrok J, Shehata ML, et al. Right and left ventricular myocardial perfusion reserves correlate with right. Radiology 2011;258:119-27.

25. Meloche J, Lampron MC, Nadeau V, et al. Implication of inflammation and epigenetic readers in coronary artery remodeling in patients with pulmonary arterial hypertension. Arterioscler Thromb Vasc Biol 2017;37:1513-23.

26. Narmoneva DA, Vukmirovic R, Davis ME, et al. 
Endothelial cells promote cardiac myocyte survival and spatial reorganization: implications for cardiac regeneration. Circulation 2004;110:962-8.

27. Voelkel NF, Quaife RA, Leinwand LA, et al. Right ventricular function and failure: report of a National Heart, Lung, and Blood Institute working group on cellular and molecular mechanisms of right heart failure. Circulation 2006;114:1883-91.

28. Potus F, Ruffenach G, Dahou A, et al. Downregulation of microRNA-126 contributes to the failing right ventricle in pulmonary arterial hypertension. Circulation 2015;132:932-43.

29. Bogaard HJ, Natarajan R, Henderson SC, et al. Chronic pulmonary artery pressure elevation is insufficient to explain right heart failure. Circulation 2009;120:1951-60.

30. Drake JI, Bogaard HJ, Mizuno S, et al. Molecular signature of a right heart failure program in chronic severe pulmonary hypertension. Am J Respir Cell Mol Biol 2011;45:1239-47.

31. Piao L, Fang YH, Parikh K, et al. Cardiac glutaminolysis: a maladaptive cancer metabolism pathway in the right ventricle in pulmonary hypertension. J Mol Med (Berl) 2013;91:1185-97.

32. Partovian C, Adnot S, Eddahibi S, et al. Heart and lung VEGF mRNA expression in rats with monocrotaline- or hypoxia-induced pulmonary hypertension. Am J Physiol 1998;275:H1948-56.

33. Suen CM, Chaudhary KR, Deng Y, et al. Fischer rats exhibit maladaptive structural and molecular right ventricular remodelling in severe pulmonary hypertension: a genetically prone model for right heart failure. Cardiovasc Res 2019;115:788-99.

34. Legchenko E, Chouvarine P, Borchert P, et al. PPAR agonist pioglitazone reverses pulmonary hypertension and prevents right heart failure via fatty acid oxidation. Sci Transl Med 2018;10:eaao0303.

35. Kolb TM, Peabody J, Baddoura P, et al. Right ventricular angiogenesis is an early adaptive response to chronic hypoxia-induced pulmonary hypertension. Microcirculation 2015;22:724-36.

36. Lahm T, Albrecht M, Fisher AJ, et al. 17 $\beta$-Estradiol attenuates hypoxic pulmonary hypertension via estrogen receptor-mediated effects. Am J Respir Crit Care Med 2012;185:965-80.

37. Graham BB, Koyanagi D, Kandasamy B, et al. Right ventricle vasculature in human pulmonary hypertension assessed by stereology. Am J Respir Crit Care Med 2017;196:1075-77.
38. Gómez A, Bialostozky D, Zajarias A, et al. Right ventricular ischemia in patients with primary pulmonary hypertension. J Am Coll Cardiol 2001;38:1137-42 .

39. Ruiter G, Ying Wong Y, de Man FS, et al. Right ventricular oxygen supply parameters are decreased in human and experimental pulmonary hypertension. J Heart Lung Transplant 2013;32:231-40.

40. Reddy S, Zhao M, Hu DQ, et al. Dynamic microRNA expression during the transition from right ventricular hypertrophy to failure. Physiol Genomics 2012;44:562-75.

41. Chouvarine P, Geldner J, Giagnorio R, et al. Trans-rightventricle and transpulmonary microRNA gradients in human pulmonary arterial hypertension. Pediatr Crit Care Med 2020;21:340-9.

42. Frump AL, Bonnet S, de Jesus Perez VA, et al. Emerging role of angiogenesis in adaptive and maladaptive right ventricular remodeling in pulmonary hypertension. Am J Physiol Lung Cell Mol Physiol 2018;314:L443-60.

43. Sutendra G, Dromparis P, Paulin R, et al. A metabolic remodeling in right ventricular hypertrophy is associated with decreased angiogenesis and a transition from a compensated to a decompensated state in pulmonary hypertension. J Mol Med (Berl) 2013;91:1315-27.

44. Tamosiuniene $\mathrm{R}$, Manouvakhova $\mathrm{O}$, Mesange $\mathrm{P}$, et al. Dominant role for regulatory $T$ cells in protecting females against pulmonary hypertension. Circ Res 2018;122:1689-702.

45. Damico R, Kolb TM, Valera L, et al. Serum endostatin is a genetically determined predictor of survival in pulmonary arterial hypertension. Am J Respir Crit Care Med 2015;191:208-18.

46. Bogaard HJ, Natarajan R, Mizuno S, et al. Adrenergic receptor blockade reverses right heart remodeling and dysfunction in pulmonary hypertensive rats. Am J Respir Crit Care Med 2010;182:652-60.

47. Umar S, Iorga A, Matori H, et al. Estrogen rescues preexisting severe pulmonary hypertension in rats. Am J Respir Crit Care Med 2011;184:715-23.

48. Frump AL, Goss KN, Vayl A, et al. Estradiol improves right ventricular function in rats with severe angioproliferative pulmonary hypertension: effects of endogenous and exogenous sex hormones. Am J Physiol Lung Cell Mol Physiol 2015;308:L873-90.

49. Matori H, Umar S, Nadadur RD, et al. Genistein, a soy phytoestrogen, reverses severe pulmonary hypertension and prevents right heart failure in rats. Hypertension 2012;60:425-30.

50. Alzoubi A, Toba M, Abe K, et al. Dehydroepiandrosterone 
restores right ventricular structure and function in rats with severe pulmonary arterial hypertension. Am J Physiol Heart Circ Physiol 2013;304:H1708-18.

51. Handoko ML, de Man FS, Happé CM, et al. Opposite effects of training in rats with stable and progressive pulmonary hypertension. Circulation 2009;120:42-9.

52. van Albada ME, Berger RMF, Niggebrugge $M$, et al. Prostacyclin therapy increases right ventricular capillarisation in a model for flow-associated pulmonary hypertension. Eur J Pharmacol 2006;549:107-16.

53. Abdul-Ghani M, Suen C, Jiang B, et al. Cardiotrophin 1 stimulates beneficial myogenic and vascular remodeling of the heart. Cell Res 2017;27:1195-215.

54. Lahm T, Douglas IS, Archer SL, et al. Assessment of right ventricular function in the research setting: knowledge gaps and pathways forward. An Official American Thoracic Society Research Statement. Am J Respir Crit Care Med 2018;198:e15-43.

55. Mendelsohn ME, Karas RH. The protective effects of estrogen on the cardiovascular system. N Engl J Med 1999;340:1801-11.

56. Mendelsohn ME, Karas RH. Molecular and cellular basis of cardiovascular gender differences. Science 2005;308:1583-7.

57. Thum T, Borlak J. Testosterone, cytochrome P450, and cardiac hypertrophy. FASEB J 2002;16:1537-49.

58. Thum T, Borlak J. Gene expression in distinct regions of the heart. Lancet 2000;355:979-83.

59. Humbert M, Sitbon O, Chaouat A, et al. Survival in patients with idiopathic, familial, and anorexigenassociated pulmonary arterial hypertension in the modern management era. Circulation 2010;122:156-63.

60. Olsson KM, Delcroix M, Ghofrani HA, et al. Anticoagulation and survival in pulmonary arterial hypertension: Results from the comparative, prospective registry of newly initiated therapies for pulmonary hypertension (COMPERA). Circulation 2014;129:57-65.

61. Escribano-Subias P, Blanco I, López-Meseguer M, et al. Survival in pulmonary hypertension in Spain: insights from the Spanish registry. Eur Respir J 2012;40:596-603.

62. Benza RL, Miller DP, Gomberg-Maitland M, et al. Predicting survival in pulmonary arterial hypertension: Insights from the registry to evaluate early and long-term pulmonary arterial hypertension disease management (REVEAL). Circulation 2010;122:164-72.

63. Jacobs W, van de Veerdonk MC, Trip P, et al. The right ventricle explains sex differences in survival in idiopathic pulmonary arterial hypertension. Chest 2014;145:1230-6.
64. Kawut SM, Al-Naamani N, Agerstrand C, et al. Determinants of right ventricular ejection fraction in pulmonary arterial hypertension. Chest 2009;135:752-9.

65. Swift AJ, Capener D, Hammerton C, et al. Right ventricular sex differences in patients with idiopathic pulmonary arterial hypertension characterised by magnetic resonance imaging: pair-matched case controlled study. PLoS One 2015;10:e0127415.

66. Ventetuolo CE, Praestgaard A, Palevsky HI, et al. Sex and haemodynamics in pulmonary arterial hypertension. Eur Respir J 2014;43:523-30.

67. Melenovsky V, Hwang SJ, Lin G, et al. Right heart dysfunction in heart failure with preserved ejection fraction. Eur Heart J 2014;35:3452-62.

68. Prins KW, Rose L, Archer SL, et al. Clinical determinants and prognostic implications of right ventricular dysfunction in pulmonary hypertension caused by chronic lung disease. J Am Heart Assoc 2019;8:e011464.

69. Ventetuolo CE, Hess E, Austin ED, et al. Sex-based differences in veterans with pulmonary hypertension: results from the veterans affairs-clinical assessment reporting and tracking database. PLoS One 2017;12:e0187734.

70. Ventetuolo CE, Ouyang P, Bluemke DA, et al. Sex hormones are associated with right ventricular structure and function: the MESA-right ventricle study. Am J Respir Crit Care Med 2011;183:659-67.

71. Ventetuolo CE, Mitra N, Wan F, et al. Oestradiol metabolism and androgen receptor genotypes are associated with right ventricular function. Eur Respir J 2016;47:553-63.

72. Baird GL, Archer-Chicko C, Barr RG, et al. Lower DHEA-S levels predict disease and worse outcomes in post-menopausal women with idiopathic, connective tissue disease- and congenital heart disease-associated pulmonary arterial hypertension. Eur Respir J 2018;5 1:1800467.

73. Lahm T, Tuder RM, Petrache I. Progress in solving the sex hormone paradox in pulmonary hypertension. Am J Physiol Lung Cell Mol Physiol 2014;307:L7-26.

74. Lahm T, Frump AL, Albrecht ME, et al. 17 -Estradiol mediates superior adaptation of right ventricular function to acute strenuous exercise in female rats with severe pulmonary hypertension. Am J Physiol Lung Cell Mol Physiol 2016;311:L375-88.

75. Liu A, Schreier D, Tian L, et al. Direct and indirect protection of right ventricular function by estrogen in an experimental model of pulmonary arterial hypertension. Am J Physiol Heart Circ Physiol 2014;307:H273-83. 
76. Liu A, Philip J, Vinnakota KC, et al. Estrogen maintains mitochondrial content and function in the right ventricle of rats with pulmonary hypertension. Physiol Rep 2017;5:e13157.

77. Liu A, Hacker T, Eickhoff JC, et al. Estrogen preserves pulsatile pulmonary arterial hemodynamics in pulmonary arterial hypertension. Ann Biomed Eng 2017;45:632-43.

78. Philip JL, Tabima DM, Wolf GD, et al. Exogenous estrogen preserves distal pulmonary arterial mechanics and prevents pulmonary hypertension in rats. Am J Respir Crit Care Med 2020;201:371-4.

79. Hemnes AR, Maynard KB, Champion HC, et al. Testosterone negatively regulates right ventricular load stress responses in mice. Pulm Circ 2012;2:352-8.

80. Nakamura S, Yoshimura M, Nakayama M, et al. Possible association of heart failure status with synthetic balance between aldosterone and dehydroepiandrosterone in human heart. Circulation 2004;110:1787-93.

81. Mannic T, Mouffok M, Python M, et al. DHEA prevents mineralo- and glucocorticoid receptor-induced chronotropic and hypertrophic actions in isolated rat cardiomyocytes. Endocrinology 2013;154:1271-81.

82. Ventetuolo CE, Baird GL, Barr RG, et al. Higher estradiol and lower dehydroepiandrosterone-sulfate levels are associated with pulmonary arterial hypertension in men. Am J Respir Crit Care Med 2016;193:1168-75.

83. Lahm T, Frump AL. Toward harnessing sex steroid signaling as a therapeutic target in pulmonary arterial hypertension. Am J Respir Crit Care Med 2017;195:284-6.

84. Kawut SM, Archer-Chicko CL, DeMichele A, et al. Anastrozole in pulmonary arterial hypertension. A randomized, double-blind, placebo-controlled trial. Am J Respir Crit Care Med 2017;195:360-8.

85. Kawut SM, Pinder D, Al-Naamani N, et al. Fulvestrant for the treatment of pulmonary arterial hypertension. Ann Am Thorac Soc 2019;16:1456-9.

86. Quaife RA, Chen MY, Lynch D, et al. Importance of right ventricular end-systolic regional wall stress in idiopathic pulmonary arterial hypertension: a new method for estimation of right ventricular wall stress. Eur J Med Res 2006;11:214-20.

87. Kusachi S, Nishiyama O, Yasuhara K, et al. Right and left ventricular oxygen metabolism in open-chest dogs. Am J Physiol 1982;243:H761-6.

88. Bing RJ, Siegel A, Vitale A, et al. Metabolic studies on the human heart in vivo. I. Studies on carbohydrate metabolism of the human heart. Am J Med 1953;15:284-96.
89. Lopaschuk GD. Metabolic modulators in heart disease: past, present, and future. Can J Cardiol 2017;33:838-49.

90. Randle PJ, Priestman DA, Mistry SC, et al. Glucose fatty acid interactions and the regulation of glucose disposal. J Cell Biochem 1994;55:1-11.

91. Talati M, Hemnes A. Fatty acid metabolism in pulmonary arterial hypertension: Role in right ventricular dysfunction and hypertrophy. Pulmonary Circulation 2015;5:269-78.

92. van der Vusse GJ, van Bilsen M, Glatz JF. Cardiac fatty acid uptake and transport in health and disease. Cardiovasc Res 2000;45:279-93.

93. Stanley WC, Lopaschuk GD, Hall JL, et al. Regulation of myocardial carbohydrate metabolism under normal and ischaemic conditions. Cardiovasc Res 1997;33:243-57.

94. Xu W, Koeck T, Lara AR, et al. Alterations of cellular bioenergetics in pulmonary artery endothelial cells. Proc Natl Acad Sci U S A 2007;104:1342-7.

95. Brittain EL, Talati M, Fessel JP, et al. Fatty acid metabolic defects and right ventricular lipotoxicity in human pulmonary arterial hypertension. Circulation 2016;133:1936-44.

96. Hemnes AR, Brittain EL, Trammell AW, et al. Evidence for right ventricular lipotoxicity in heritable pulmonary arterial hypertension. Am J Respir Crit Care Med 2014;189:325-34.

97. Egnatchik RA, Brittain EL, Shah AT, et al. Dysfunctional BMPR2 signaling drives an abnormal endothelial requirement for glutamine in pulmonary arterial hypertension. Pulm Circ 2017;7:186-99.

98. Brown DA, Perry JB, Allen ME, et al. Expert consensus document: mitochondrial function as a therapeutic target in heart failure. Nat Rev Cardiol 2017;14:238-50.

99. Mishra P, Chan DC. Metabolic regulation of mitochondrial dynamics. J Cell Biol 2016;212:379-87.

100. Galloway CA, Lee H, Yoon Y. Mitochondrial morphologyemerging role in bioenergetics. Free Radic Biol Med 2012;53:2218-28.

101. Piquereau J, Caffin F, Novotova M, et al. Mitochondrial dynamics in the adult cardiomyocytes: which roles for a highly specialized cell? Front Physiol 2013;4:102.

102. Neubauer S. The failing heart--an engine out of fuel. $\mathrm{N}$ Engl J Med 2007;356:1140-51.

103. Gomez-Arroyo J, Mizuno S, Szczepanek K, et al. Metabolic gene remodeling and mitochondrial dysfunction in failing right ventricular hypertrophy secondary to pulmonary arterial hypertension. Circ Heart Fail 2013;6:136-44.

104. Ye JX, Wang SS, Ge M, et al. Suppression of endothelial 
PGC- $1 \alpha$ is associated with hypoxia-induced endothelial dysfunction and provides a new therapeutic target in pulmonary arterial hypertension. Am J Physiol Lung Cell Mol Physiol 2016;310:L1233-42.

105.Hansmann G, Calvier L, Risbano MG, et al. Activation of the metabolic master regulator PPAR $\gamma$ : a potential pioneering therapy for pulmonary arterial hypertension. Am J Respir Cell Mol Biol 2020;62:143-56.

106. Qipshidze N, Tyagi N, Metreveli N, et al. Autophagy mechanism of right ventricular remodeling in murine model of pulmonary artery constriction. Am J Physiol Heart Circ Physiol 2012;302:H688-96.

107.Yu Q, Chan SY. Mitochondrial and metabolic drivers of pulmonary vascular endothelial dysfunction in pulmonary hypertension. Adv Exp Med Biol 2017;967:373-83.

108. Marsboom G, Toth PT, Ryan JJ, et al. Dynaminrelated protein 1-mediated mitochondrial mitotic fission permits hyperproliferation of vascular smooth muscle cells and offers a novel therapeutic target in pulmonary hypertension. Circ Res 2012;110:1484-97.

109. De Jong KA, Lopaschuk GD. Complex energy metabolic changes in heart failure with preserved ejection fraction and heart failure with reduced ejection fraction. Can J Cardiol 2017;33:860-71.

110. Neely JR, Morgan HE. Relationship between carbohydrate and lipid metabolism and the energy balance of heart muscle. Annu Rev Physiol 1974;36:413-59.

111.Oikawa M, Kagaya Y, Otani H, et al. Increased [18F] fluorodeoxyglucose accumulation in right ventricular free wall in patients with pulmonary hypertension and the effect of epoprostenol. J Am Coll Cardiol 2005;45:1849-55.

112. Piao L, Fang YH, Cadete VJJ, et al. The inhibition of pyruvate dehydrogenase kinase improves impaired cardiac function and electrical remodeling in two models of right ventricular hypertrophy: Resuscitating the hibernating right ventricle. J Mol Med 2010;88:47-60.

113. Michelakis ED, Gurtu V, Webster L, et al. Inhibition of pyruvate dehydrogenase kinase improves pulmonary arterial hypertension in genetically susceptible patients. Sci Transl Med 2017;9:eaao4583.

114. Paulin R, Dromparis P, Sutendra G, et al. Sirtuin 3 deficiency is associated with inhibited mitochondrial function and pulmonary arterial hypertension in rodents and humans. Cell Metab 2014;20:827-39.

115. Stacpoole PW, Martyniuk CJ, James MO, et al. Dichloroacetate-induced peripheral neuropathy. Int Rev Neurobiol 2019;145:211-38.
116. Brandsma D, Dorlo TP, Haanen JH, et al. Severe encephalopathy and polyneuropathy induced by dichloroacetate. J Neurol 2010;257:2099-100.

117. Chouvarine P, Giera M, Kastenmüller G, et al. Transright ventricle and transpulmonary metabolite gradients in human pulmonary arterial hypertension. Heart 2020;106:1332-41.

118. Tuder RM, Robinson JC, Graham BB. Fat and cardiotoxicity in hereditary pulmonary hypertension. Am J Respir Crit Care Med 2014;189:247-9.

119. Coburn CT, Knapp J, Febbraio M, et al. Defective uptake and utilization of long chain fatty acids in muscle and adipose tissues of CD36 knockout mice. J Biol Chem 2000; 275: 32523-32529.

120. Febbraio M, Abumrad NA, Hajjar DP, et al. A null mutation in murine CD36 reveals an important role in fatty acid and lipoprotein metabolism. J Biol Chem 1999;274:19055-62.

121.Lankeit M, Dellas C, Panzenböck A, et al. Heart-type fatty acid-binding protein for risk assessment of chronic thromboembolic pulmonary hypertension. Eur Respir J 2008;31:1024-9.

122. Nagaya N, Goto Y, Satoh T, et al. Impaired regional fatty acid uptake and systolic dysfunction in hypertrophied right ventricle. J Nucl Med 1998;39:1676-80.

123. Randle PJ, Garland PB, Hales CN, et al. The glucose fatty-acid cycle. Its role in insulin sensitivity and the metabolic disturbances of diabetes mellitus. Lancet 1963;1:785-9.

124.Lai YC, Tabima DM, Dube JJ, et al. SIRT3-AMPactivated protein kinase activation by nitrite and metformin improves hyperglycemia and normalizes pulmonary hypertension associated with heart failure with preserved ejection fraction. Circulation 2016;133:717-31.

125. Dean A, Nilsen M, Loughlin L, et al. Metformin reverses development of pulmonary hypertension via aromatase inhibition. Hypertension 2016;68:446-54.

126. Brittain EL, Talati M, Fortune N, et al. Adverse physiologic effects of Western diet on right ventricular structure and function: role of lipid accumulation and metabolic therapy. Pulm Circ 2019;9:2045894018817741.

127. Rena G, Hardie DG, Pearson ER. The mechanisms of action of metformin. Diabetologia 2017;60:1577-85.

128.El-Beshlawy A, Youssry I, El-Saidi S, et al. Pulmonary hypertension in $\beta$-thalassemia major and the role of L-carnitine therapy. Pediatr Hematol Oncol 2008;25:734-43.

129.Hansmann G, Wagner RA, Schellong S, et al. Pulmonary 
arterial hypertension is linked to insulin resistance and reversed by peroxisome proliferator-activated receptorgamma activation. Circulation 2007;115:1275-84.

130.Zamanian RT, Hansmann G, Snook S, et al. Insulin resistance in pulmonary arterial hypertension. Eur Respir J 2009;33:318-24.

131.Hemnes AR, Luther JM, Rhodes CJ, et al. Human PAH is characterized by a pattern of lipid-related insulin resistance. JCI Insight 2019;4:e123611.

132.Pugh ME, Robbins IM, Rice TW, et al. Unrecognized glucose intolerance is common in pulmonary arterial hypertension. J Heart Lung Transplant 2011;30:904-11.

133. West J, Niswender KD, Johnson JA, et al. A potential role for insulin resistance in experimental pulmonary hypertension. Eur Respir J 2013;41:861-71.

134. Trammell AW, Talati M, Blackwell TR, et al. Pulmonary vascular effect of insulin in a rodent model of pulmonary arterial hypertension. Pulm Circ 2017;7:624-34.

135.Kim JA, Wei Y, Sowers JR. Role of mitochondrial dysfunction in insulin resistance. Circ Res 2008;102:401-14.

136. Czech MP, Tencerova M, Pedersen DJ, et al. Insulin signalling mechanisms for triacylglycerol storage. Diabetologia 2013;56:949-64.

137.Hansmann G, De Jesus Perez VA, Alastalo TP, et al. An antiproliferative BMP-2/PPAR $\gamma / \mathrm{apoE}$ axis in human and murine SMCs and its role in pulmonary hypertension. J Clin Invest 2008;118:1846-57.

138. Hemnes AR, Fessel JP, Chen X, et al. BMPR2 dysfunction impairs insulin signaling and glucose homeostasis in cardiomyocytes. Am J Physiol Lung Cell Mol Physiol 2020;318:L429-41.

139.Johnson EK, Matkovich SJ, Nerbonne JM. Regional differences in mRNA and lncRNA expression profiles in non-failing human atria and ventricles. Sci Rep 2018;8:13919.

140. Tadic M, Vukomanovic V, Cuspidi C, et al. The relationship between right ventricular deformation and heart rate variability in asymptomatic diabetic patients. J Diabetes Complications 2017;31:1152-7.

141. Berceanu M, Mirea O, Târtea GC, et al. The significance of right ventricle in young subjects with diabetes mellitus type 1 . An echocardiographyic study. Curr Health Sci J 2019;45:174-8.

142. Kosmala W, Colonna P, Przewlocka-Kosmala M, et al. Right ventricular dysfunction in asymptomatic diabetic patients. Diabetes Care 2004;27:2736-8.

143. Gopal DM, Santhanakrishnan R, Wang YC, et al.
Impaired right ventricular hemodynamics indicate preclinical pulmonary hypertension in patients with metabolic syndrome. J Am Heart Assoc 2015;4:e01597.

144. Mey JT, Hari A, Axelrod CL, et al. Lipids and ketones dominate metabolism at the expense of glucose control in pulmonary arterial hypertension: a hyperglycaemic clamp and metabolomics study. Eur Respir J 2020;5 5:1901700.

145. Yang L, Venneti S, Nagrath D. Glutaminolysis: a hallmark of cancer metabolism. Annu Rev Biomed Eng 2017;19:163-94.

146. Stenmark KR, Meyrick B, Galie N, et al. Animal models of pulmonary arterial hypertension: the hope for etiological discovery and pharmacological cure. Am J Physiol Lung Cell Mol Physiol 2009;297:L1013-32.

147.Anderson A, van der Feen D, Andersen S, et al. Animal models of right heart failure. Cardiovasc Diagn Ther 2020;10:1561-79.

148. Bernando RJ, Haddad F, Couture E, et al. Mechanics of right ventricular dysfunction in pulmonary arterial hypertension and heart failure with preserved ejection fraction. Cardiovasc Diagn Ther 2020;10:1580-1603.

149. Truong U, Meinel K, Haddad F, et al. Update on noninvasive imaging of right ventricle dysfunction in pulmonary hypertension. Cardiovasc Diagn Ther 2020;10:1604-24.

150.Sanders JL, Koestenberger M, Rosenkranz S, et al. Right ventricular dysfunction and long-term risk of death. Cardiovasc Diagn Ther 2020;10:1646-58.

151.Kiskin FN, Chang CH, Huang CJZ, et al. Contributions of BMPR2 mutations and extrinsic factors to cellular phenotypes of pulmonary arterial hypertension revealed by induced pluripotent stem cell modeling. Am J Respir Crit Care Med 2018;198:271-5.

152.Sa S, Gu M, Chappell J, et al. Induced pluripotent stem cell model of pulmonary arterial hypertension reveals novel gene expression and patient specificity. Am J Respir Crit Care Med 2017;195:930-41.

153. West JD, Carrier EJ. Precision modeling of pulmonary hypertension pathology with induced pluripotent stem cell-derived cells. Am J Respir Crit Care Med 2018;198:154-5.

154. Chen IY, Matsa E, Wu JC. Induced pluripotent stem cells: at the heart of cardiovascular precision medicine. Nat Rev Cardiol 2016;13:333-49.

155. Wang L, Kim K, Parikh S, et al. Hypertrophic cardiomyopathy-linked mutation in troponin $\mathrm{T}$ causes myofibrillar disarray and pro-arrhythmic action potential changes in human iPSC cardiomyocytes. J Mol Cell 
Cardiol 2018;114:320-7.

156. D'Amico RW, Faley S, Shim H-N, et al. Pulmonary vascular platform models the effects of flow and pressure on endothelial dysfunction in BMPR2 associated pulmonary arterial hypertension. Int J Mol Sci 2018;19:2561.

157. Tiburcy M, Hudson JE, Balfanz P, et al. Defined engineered human myocardium with advanced maturation for applications in heart failure modeling and repair. Circulation 2017;135:1832-47.

158. Andersen P, Tampakakis E, Jimenez DV, et al. Precardiac organoids form two heart fields via Bmp/Wnt signaling. Nat Commun 2018;9:3140.

159.Feaster TK, Cadar AG, Wang L, et al. Matrigel Mattress. Circ Res 2015;117:995-1000.

160.Assad TR, Hemnes AR, Larkin EK, et al. Clinical and biological insights into combined post- and precapillary pulmonary hypertension. J Am Coll Cardiol 2016;68:2525-36.

161. D’Alto M, Motoji Y, Romeo E, et al. Fluid challenge predicts clinical worsening in pulmonary arterial hypertension. Int J Cardiol 2018;261:167-71.

162.Agrawal V, D'Alto M, Naeije R, et al. Echocardiographic detection of occult diastolic dysfunction in pulmonary hypertension after fluid challenge. J Am Heart Assoc 2019;8:e012504.

163. Agrawal V, Fortune N, Yu S, et al. Natriuretic peptide receptor $\mathrm{C}$ contributes to disproportionate right ventricular hypertrophy in a rodent model of obesity-induced heart failure with preserved ejection fraction with pulmonary hypertension. Pulm Circ 2019;9:2045894019878599.

164.Meng Q, Lai YC, Kelly NJ, et al. Development of a mouse model of metabolic syndrome, pulmonary hypertension, and heart failure with preserved ejection fraction. Am J Respir Cell Mol Biol 2017;56:497-505.

165. Klinger JR, Thaker S, Houtchens J, et al. Pulmonary hemodynamic responses to brain natriuretic peptide and sildenafil in patients with pulmonary arterial hypertension. Chest 2006;129:417-25.

166. Klinger JR. The nitric oxide/cGMP signaling pathway in pulmonary hypertension. Clin Chest Med 2007;28:143-67.

167. Melenovsky V, Al-Hiti H, Kazdova L, et al.

Transpulmonary B-type natriuretic peptide uptake and cyclic guanosine monophosphate release in heart failure and pulmonary hypertension. J Am Coll Cardiol 2009;54:595-600.

168. Monahan K, Scott TA, Su YR, et al. Reproducibility of intracardiac and transpulmonary biomarkers in the evaluation of pulmonary hypertension. Pulm Circ 2013;3:345-9.

Cite this article as: Agrawal V, Lahm T, Hansmann G, Hemnes AR. Molecular mechanisms of right ventricular dysfunction in pulmonary arterial hypertension: focus on the coronary vasculature, sex hormones, and glucose/lipid metabolism. Cardiovasc Diagn Ther 2020;10(5):1522-1540. doi: $10.21037 / \mathrm{cdt}-20-404$ 